\title{
Integrating International Exchange Students into Local Service-Learning Projects in Hong Kong
}

\author{
Maureen Yin Lee Chan ${ }^{1}$ and Robin Stanley Snell ${ }^{2}$ \\ ${ }^{1}$ Department of Curriculum and Instruction, The Education University of Hong Kong, ${ }^{2}$ Department of Management, \\ Lingnan University
}

Cite as: Chan, M.Y.L., Snell, R.S., (2021). Integrating International Exchange Students into Local Service-Learning Projects in Hong Kong. Metrpolitan Universities, 32(1), 54-77. DOI: 10.18060/24272

This is an open access article distributed under the terms of the Creative Commons Attribution License.

Editor: Valerie L. Holton, Ph.D.

\begin{abstract}
Through qualitative research, which involved qualitative interviews and focus group meetings with members of four student teams, we identified a number of barriers to the development of cohesiveness in teams of local and international exchange (IE) students, who were undertaking service-learning (SL) together. Lack of cohesiveness in such teams resulted in the psychological withdrawal of some of the IE students and appeared to reduce opportunities to derive developmental benefits. Barriers to cohesiveness identified by the students included language, conflicting priorities, and East-West cultural differences. We also identified how students took action to remove the barriers to cohesiveness. These actions included conducting internal team meetings in English and arranging for local students to provide interpretation in meetings with community stakeholders. Students reported that the major developmental benefits associated specifically with working cohesively in a cross-cultural team were improved English language skills, greater interpersonal adaptability, and appreciation of diversity. We offer practical suggestions about how educators can prepare local and IE students to work together effectively on SL projects and about further research. Studies of projects undertaken by inter-cultural SL teams at host universities in other jurisdictions would facilitate the generalizability of the findings.
\end{abstract}

Keywords: cohesiveness, cultural differences, communication strategies, developmental outcomes 


\section{Introduction}

It has become a mainstream educational practice in tertiary education to arrange for students to undertake projects that involve applying academic knowledge to real-life situations beyond the classroom through experiential learning (DiCecco et al., 2004; Gilbert et al., 2014). Such outside-the-classroom learning platforms include service-learning (SL), internships, and workintegrated learning, which typically aim to develop students' practical and transferable skills (Brail, 2016), along with international exchange (IE) programs, which seek to equip students for globalization (Chak \& Makino, 2010; Gallarza et al., 2017). Both IE and SL programs have been identified as experiential learning platforms with high developmental impact. Niehaus and Crain (2013) observe that the prevalence of SL opportunities and IE experiences has increased, and that programs combining the two are no longer unusual. In this paper, we shall investigate students' experience of SL projects that were undertaken by mixed teams of local and IE students.

SL requires students to put academic knowledge into practice, along with contributing to community development through collaboration with one or more community service agencies. Conway et al. (2009) recommend that educators increase their use of SL, and this view is supported by Yorio and Ye (2012), who found that SL has a positive effect both on students' understanding of social issues and on their cognitive development. SL has also been found to give rise to a host of other positive developmental outcomes, including greater sensitivity, relationship and team skills, and self-awareness (Conner \& Erickson, 2017; Lau \& Snell, 2021; Snell \& Lau, 2020; Wilson, 2011).

Globalization has enabled a large number of students to leave their home countries to pursue higher education and has had a profound impact on higher education (Chelliah et al., 2018). Chak and Makino (2010) regard IE programs as involving out-of-classroom experiential learning activities. During IE placements, students can develop communication skills experientially, through interpersonal contact with different yet similarly situated others, and such contact can have deep personal impact (San Antonio \& Ofori-Dwumfuo, 2015). Engaging in SL in collaboration with local students might therefore appear to have potential to induce additional developmental impact for IE students.

However, the quality of the team experience when undertaking SL projects, reflecting team cohesiveness, has a major impact on student development (Falk, 2012; Snell et al., 2015), but in cross-cultural contexts this may vary considerably, such that undertaking SL may not always be an effective platform for the development of IE students and their local counterparts. Prior studies have focused on the role of leadership, culture, structure, and goal clarity in enhancing team cohesiveness (Riordan \& Weatherly, 1999; Wendt et al., 2009), but relatively little is known about how students' behavior can facilitate or impede the development of cohesiveness in crosscultural contexts.

(C) The Author 2021. Published by the Coalition of Urban and Metropolitan Universities. www.cumuonline.org Metropolitan Universities | DOI 10.18060/24272 | February 15, 2021 
The research for this paper is motivated by the view that educators bear some responsibility for fostering cohesiveness within student teams (Williams et al., 2006). It is based on interviews with local and IE students, who worked in four culturally mixed SL project teams based at a university in Hong Kong. We shall draw on intergroup contact theory (Allport, 1954; Ryan, 2016) as a framework for analyzing cross-cultural interactions in the context of SL. The paper addresses three research questions. First, what are the potential barriers to integrating IE students into SL project teams with local members? Second, what are the processes that facilitate the development of inter-cultural cohesiveness within the teams? Third, what are the potential benefits arising from inter-cultural team cohesiveness in the context of SL? Based on the findings, we shall identify theoretical contributions and suggest practical steps for developing cohesiveness among culturally mixed teams in the context of SL.

\section{Literature Review}

Team Cohesiveness and Its Importance in SL

Team cohesiveness is experienced as solidarity, harmony, energy, and mutual commitment among members (Müceldili \& Erdil, 2015; Quinn \& Dutton, 2005). It is reflected in members' mutual attraction (Williams et al., 2006) and in their desire to remain on the team (Campion et al., 1993). It may be defined as the extent to which a team works in unity toward a common goal while also meeting the emotional needs of the members (Carron \& Brawley, 2000). Team cohesiveness may thus be construed as comprising the two dimensions of task cohesiveness and social cohesiveness, which converge when team members form attachment in order to achieve objectives (Ötkan et al., 2017). Cohesive student teams have strong potential to induce positive developmental outcomes (Williams et al., 2006). We consider that team cohesiveness is an important success factor in SL, which unlike other kinds of team assignment requires members to meet frequently and do relatively more of the project work together, and relatively less of it individually as delegated parts. A quote at the beginning of the findings section will illustrate this point. In the context of SL, the nature of both within-team interactions and interactions between student teams and community stakeholders are important processes that govern whether team cohesiveness is achieved.

\section{Potential Barriers to Cohesiveness}

Various cross-cultural and other contextual barriers can impede the development of effective team relationships between IE students and local students (Barna, 1997; Jang \& Kim, 2010; Sato $\&$ Hodge, 2013; Yakuina et al., 2013). We shall identify four domains where barriers may arise.

Cultural Preferences. Differences in cultural values and failure to appreciate such differences, may impede IE students' ability to establish relationships with local students (Barna, 1997; Wen et al., 2018). Studies by Hofstede $(2001,2005)$ have indicated that the majority of cultures 
characterized as Western, such as those in the United States, Western Europe, New Zealand, and Australia, tend toward individualism, whereas most cultures in East Asia, Africa, and Latin America tend toward collectivism. In Hong Kong, collectivism prevails as a cultural norm (Triandis et al.,1988), while many IE students come from Western cultures. LeFebvre and Franke (2013) characterize the core elements of individualism as independence and uniqueness, versus those of collectivism as duty and in-group orientation. Individualists tend to focus more on individual responsibility, assertiveness, and competitiveness, whereas collectivists are more inclined to seek advice from others, engage in relationship-building, strive to maintain harmony within the group, and respond to group pressure (LeFebvre \& Franke, 2013). Individualists tend to value pleasure, achievement, competition, and autonomy, while collectivists prefer to emphasize security and obedience, and selectively strive to maintain cohesion within those groups with which they identify (Nibler \& Harris, 2003). Failure to appreciate differences in cultural value preferences may constitute a barrier to the development of cohesiveness within internationally diverse student teams.

Language Barriers. Language barriers constitute another potential barrier to the development of cohesiveness in cross-cultural student teams (Barna, 1997; Keles, 2013; Wen et al., 2018). Lack of proficiency among group members in a common language medium is generally acknowledged to impede the development of team involvement and group trust (Lagerstrom \& Andersson, 2003; Lauring \& Selmer, 2010), but appropriate communication strategies may overcome this barrier.

Contact Relationships. Empirical studies have demonstrated a tendency for IE students to socialize and develop friendships with one another rather than with local students (Brooks et al., 2015; Fincher \& Shaw, 2009; Tian, 2019; Waters \& Brooks, 2011). Ryan (2016, p.16) infers from the research of Ladegaard (2015) that the mere presence of different cultural groups of students on campuses does not naturally lead to positive intercultural interactions with local students but rather that a positive context for such interactions needs to be created by university administrators and instructors. Tian (2019) notes that although support by university authorities through policies, regulations, and organizational arrangements to increase the diversity and interaction among students can help to foster cross-cultural friendships, segregation can prevail. In addition, prejudice, stereotyping, and ethnocentricity may impede the development of positive contact relationships within groups characterized by diversity (Barna, 1997; Hodson \& Dhont, 2015; Keles, 2013). According to intergroup contact theory, while favorable contact leads to cooperation and reduced prejudice, unfavorable contact results in increased tension and hostility (Tian, 2019). Allport (1954) stipulated four conditions that are needed to be met in order for prejudice to be reduced under increased contact between members of different (cultural) groups: (1) authority support, (2) equal status of the groups in the situation, (3) intergroup cooperation (i.e. working together in a team), and (4) common goals. In the context of SL, the likelihood of favorable contact and cooperation is increased by the adoption of high-quality instructional 
methods, and by strong, supportive relationships with site-supervisors or partner organization representatives (PORs) (Batchelder \& Root, 1994; Conner \& Erickson, 2017) and potentially, if appropriate actions are taken within cross-cultural teams. Intergroup contact potentially increases empathy if members are willing and are able to assume the perspective of the outgroup (Pettigrew, 2008).

Personality Factors. When going overseas for study and entering the host environment, IE students are sojourners who may experience culture shock (McKinlay et al, 1996), struggling to adapt to the strange people, tasks, and situations of an unfamiliar culture (Kim, 2001; Pitts, 2009). In addition to suffering culture shock, an individual IE student may have personality characteristics such as shyness that are relatively socially unattractive to other members, and as a result may experience reduced access to communication within the team, and may even come to be excluded from team discussions (Jehn et al., 1999; Lauring \& Selmer, 2010). This phenomenon, besides adversely affecting the marginalized member, may also be a source of discomfort and inconvenience to the other members.

\section{Methodology}

\section{Background}

The host university had launched an IE program in the early 2000s. A core component of the program was that undergraduates could choose to undertake studies for one semester at a partner university overseas, while on a reciprocal basis, partner universities arranged for their own degree-seeking students to study at the host university for one semester. By the time of data collection for the current study, the IE program had become popular among local students, such that more than half of them chose to join the program at some point in their studies, while during a given semester there were similar numbers of outgoing and incoming IE students. The host university had begun offering semester long credit-bearing SL courses for undergraduates in the mid 2000s, and like the IE program, this had also become popular among local students, the majority of whom were taking at least one credit-bearing SL course before graduation. As with all undergraduate courses at the host university, the SL courses were open to attendance by incoming IE students, so long as the latter met the stipulated academic prerequisites, if there were any.

The current research focuses on students' experiences on two SL courses, Social Marketing and Leadership and Teamwork. The aim of the Social Marketing course was to equip students with concepts, tools, and strategies of marketing to address selected social issues, while fostering in them a sense of self-responsibility and a desire to care for those around them. Each student was required to attend lectures and participate in class discussions, and to conduct an individual project as well as participate in a team-based SL project. The aim of the Leadership and 
Teamwork course was to enable students to learn the skills of communicating effectively in teams, of assuming leadership roles in team activities, and of building effective teams. Besides attending lectures and participating in class discussions, debates, games, and experiential exercises, each student was required to participate in a team-based SL project and to write a case study essay based on material distributed by the instructor.

Both courses tended to attract significant numbers of IE students, possibly because there were no academic prerequisites for them. The respective instructors, both of whom had prior experience of teaching their respective courses, arranged for some of the project teams to be composed of a mixture of local and IE students. As was standard practice at the host university, the various service-learning projects on both courses were arranged by the university's office of servicelearning (OSL) in cooperation with representatives from the respective community organizations, i.e., PORs. The following standard practices were also adopted. On both courses, at the beginning of the semester students received briefings in class by a staff member of the OSL and a teaching assistant (a student with prior experience of undertaking SL) about the nature, purposes, and developmental goals of SL, and about the various administrative procedures required for registering for the SL component of the course requirements and for receiving official recognition for completing this component. The PORs also visited the class to provide background information about the mission and activities of their respective organizations, and the nature and aims of the projects. In addition, the OSL arranged a special training workshop lasting three hours with breakout sessions to introduce students to the special needs of different groups of direct service recipients and to prepare students for contact with them. For the students on the Social Marketing course, this workshop also introduced students to various teamwork skills. However, special training on working in cross-cultural teams was not provided to students on either course. Each project team had two or three meetings with their POR during the semester to discuss their plans and review their progress.

\section{Data Collection}

Our research was inductive and qualitative (Creswell, 1998). Data were collected by the first author and a project assistant at the host university at the end of the fall semester of academic year 2013-14. Depending on their availability, students volunteering to participate in the research participated in either a focus group (Greenbaum, 1998) or in a semi-structured individual interview (Kvale, 1996). Each of these events lasted around 1 hour and 30 minutes, and followed a critical incident protocol (Bitner et al., 1990), which encouraged storytelling (Boje, 2001). The focus groups comprised either local students or IE students. The interviews and focus groups were conducted in Cantonese with the local students, and in English with the IE students. Topics comprised: (a) how students came to understand the service needs of service recipients/host organizations, (b) the challenges and learning experiences associated with team diversity during the project, (c) interpersonal relationship development during the project, (d) developmental outcomes specifically associated with cross-cultural team working, and (e) ideas for the 
improvement of SL project preparation and support arrangements for teams comprising both IE and local students.

Informants and Their Teams. A total of 9 local students ( 3 males, 6 females) and 7 IE students (4 males, 3 females) were interviewed. They participated in four teams conducting SL projects, with each team comprising a mixture of local and IE students. Table 1 lists the informants, along with the respective home country of each of the IE students, all of whom came from the West.

Table 1. List of informants from the four SL project teams

\begin{tabular}{|l|l|l|}
\hline Teams & Local students & IE students (and country) \\
\hline Team 1 & M18L & M20E, France \\
& M19L & M21E, Sweden \\
\hline Team 2 & F24L & M22E, Germany \\
& F25L & M23E, Germany \\
\hline Team 3 & F2L & F1E, USA \\
& F3L & F4E, Portugal \\
\hline Team 4 & M10L & F9E, France \\
& F11L & \\
& F12L & \\
& & \\
\hline
\end{tabular}

Codename composition: $F=$ female; $M=$ male; $L=$ local; $E=I E$.

Team 1 comprised four local and three IE students, who had studied the Leadership and Teamwork course. Four male members of this team, among whom two were local students and two were IE students, participated in the research. The participating IE students were from France and Sweden respectively. Team 1 had served an organic farm, managed by a small team of social workers and staffed by recovering psychiatric patients, who were working as ecotour guides for members of the public. The SL project had required Team 1 to design a set of social games that could be operated by the ecotour guides as part of the program for visitors to the farm. Team 1 had also organized a training workshop for the ecotour guides to learn how to operate the games.

Team 2 comprised four local and two IE students, who had studied the Leadership and Teamwork course. Two female local students, along with the two IE students, both German males, participated in the research. Team 2 had served a group of elderly people by providing training workshops for them. The aim of the workshops was to enhance the leadership and teamwork skills of the elderly people and thereby improving the quality of the committee work that the latter were undertaking for a community-based education institute. 
Team 3 comprised five local students and two IE students, who had studied the Social Marketing course. Two female local students and the two IE students, also female, who were from the USA and Portugal respectively, participated in the research. Team 3 had served groups of primary school students by running two anti-crime promotion workshops, featuring Kung Fu dance and a drama, on behalf of the Community Relations Department of the local police force. Members of Team 3 had been taught the dance by some elderly people, who had also supported Team 3 in the delivery of the workshops.

Team 4 comprised six local students and one female IE student, who had studied the Social Marketing course. One male local student, two female local students, and the one IE student, who came from France, participated in the research. On behalf of the Hong Kong government's Social Welfare Department, Team 4 had promoted volunteerism to students at a secondary school by means of a video, posters, leaflets, and booths. They had been supported in this endeavor by a selected group of senior secondary students.

\section{Procedures for Data Analysis}

The interviews and focus groups were recorded and then transcribed in English by the first author. We then adopted a form of thematic analysis (Terry et el., 2017), which was experientially oriented, focusing on the thoughts, feelings, and reported actions of the students. Our basic approach to coding and theme development was qualitative and flexible (Braun \& Clarke, 2006), working bottom-up from the data rather than emphasizing coding reliability. Initial codes were developed by the first author. In addition to a theme regarding the relative presence or absence of cross-cultural cohesiveness, three themes corresponding to what emerged as the three research questions were eventually established after revisiting the data and codes several times during extensive discussions and reviews with the second author until consensus was reached. The first theme comprised perceived barriers to the development of cross-cultural cohesiveness. The second included the processes that contributed to the development of crosscultural cohesiveness. The third comprised the perceived beneficial outcomes for students specifically associated with cross-cultural cohesiveness. We analyzed the different perspectives of local and IE students concerning these themes.

\section{Findings}

One of the students interviewed in the research pointed out the importance of cohesive teamwork in the context of service-learning:

[Doing SL] is different from taking a course which requires [traditional] team assignments. For team assignments, we can just divide up an assignment into different parts, and with appropriate allocation of assignment parts to each member, we can then do the parts on our

(C) The Author 2021. Published by the Coalition of Urban and Metropolitan Universities. www.cumuonline.org 
own. But for an SL project, we really need to come together to have discussions and to express our opinions. [F24L, Team 2].

It appeared that as the semester progressed, a sense of cohesiveness among IE and local students developed in Teams 2 and 3, and to some extent also in Team 1. One positive indication was that many local and IE students mentioned that they intended to meet one another in the future outside Hong Kong. Other indications of cohesiveness included the following:

We had a lot of fun. They [local students] really opened up ... I think we are good friends now. They really appreciate the time they had with us. [M23E, Germany, Team 2].

Our team fitted very well together as our personalities were complementary with each other. Some were quieter, and some were more outgoing. Each of us had the chance to express our ideas ... I am very lucky that we got an awesome team. [F1E, USA, Team 3].

The two [IE] students were willing to share ideas ... We all contributed to the development of this project. The feeling was good ... Every member would contribute. [F3L, Team 3].

The people from this team were open and they were not shy but would speak and laugh with us, ask us questions, trying to make conversation. Between us there were not a lot of differences. [F4E, Portugal, Team 3].

In Team 4, however, cross-cultural cohesiveness was not achieved as the IE student failed to engage in most parts of the SL project.

I felt that I didn't participate a lot in the project, I couldn't get involved as much as them [local students]. They were giving me almost nothing to do. It wasn't a good thing. You should give equal work to everyone involved ... I said give me more, I can do it, but no ... I regret that I didn't work a lot with the local students, a bit sad. [F9E, France, Team 4].

\section{Perceived Barriers to Cross-cultural Cohesiveness}

While Team 4 was the only one that had failed to achieve cross-cultural cohesiveness, students in all four teams identified barriers to cohesiveness. These comprised (1) competing priorities, (2) cultural differences, (3) lack of socialization for the IE students into common practices at the host university, (4) concern among local students that they bore an extra burden and (5) language barriers. These perceived barriers are explained and illustrated below.

Competing Priorities. Some local students perceived that, compared with themselves, the IE students emphasized extra-curricular concerns and had assigned a relatively lower priority to their SL projects. There were two associated differences in the circumstances of local students and IE students. First, grades had a material impact on the grade point average (GPA) scores of the local students but not for the IE students. Second, local students perceived that the IE 
students regarded a semester-long sojourn in Hong Kong as an opportunity for socializing and touring. For example:

Local students would finish their projects first before they would arrange social life. The [IE] students would insist on having social life every night. They had many more social activities than us ... Friday nights are party time for them, and they are not willing to have meetings then. We locals always have meetings for project discussion from $2 \mathrm{pm}$ to $8 \mathrm{pm}$ during weekends. But the [IE] students insisted not to come. [M19L, Team 1].

Comments by the IE students did not contradict such perceptions, and suggested that because of their different priorities, the IE students were relatively less readily available to join meetings of their respective project teams. For example:

It is my first time coming to Hong Kong. In Hong Kong, it is convenient for me to travel to other Asian countries, e.g. China, and it is my first time in Asia. [F9E, France, Team 4].

Cultural Differences. Local students perceived that cultural differences vis-à-vis IE students along the individualism-collectivism dimension, compounded by competing priorities in scheduling their team meetings, had posed a challenge to developing team cohesiveness. For example:

Among mainland [China] and local students, if three out of the five members agree to something, due to the team pressure, the remaining two members will accept the opinions ... Foreign people are different. The [IE] students will insist on their own views. For example, even if four members (locals) agree to have meetings during Saturdays, one of the IE students is not willing to make a change. [M19L, Team 1].

Lack of Socialization into Common Practices at the Host University. Some students identified instances where IE students found practices commonly adopted at the host university unacceptable. For example, one local student appeared to have been taken aback by the negative reactions of two German students in her team regarding the use of drawings as a means of representing ideas and reflections:

During the class, the [IE] students did not like drawing on large flip chart paper to represent our progress to the whole class. These two German students thought that this was a childish activity. We [local students] found that it was a convenient way to bring out our ideas. They [the IE students] thought that as university students we should just use words. [F24L, Team $2]$.

Another difference concerned IE students' insistence on holding meetings during standard working day hours as opposed to local students' common habit of working long into the night.

The local students stay up late a lot doing their homework. I don't know whether they are procrastinating, or whether they do not want to do their work during the day. During my 
project work with the students here, some looked tired and they mentioned doing project work until $4 \mathrm{am}$. In my home country, I went to sleep at around $10 \mathrm{pm}$. We think that it is not worth being tired tomorrow. We do more work during the day. I usually had my part done early and I urged them [local students] to have earlier meetings. I could do my part early, but they could only do their parts at the last minute and had their own stress. [F1E, USA, Team 3].

Concern among Local Students about Bearing an Extra Burden. Comments indicated that there was some reluctance among local students to work with IE students students because of the assumed extra effort entailed by the presence of the latter.

It may be that they [locals] are more relaxed when they work with other locals. But with us [IE students], not everyone speaks English easily and they [locals] have to try even harder. [M21E, Sweden, Team 1].

When forming teams, we [local students] wanted only local students as teammates. This was because our service targets were local school students and we assumed that the [IE] students would not be familiar with the local culture and would make things more difficult for the team. [F3L, Team 3].

When I discovered that she [an IE student] came from France ... I assumed that she would act in a more relaxed, slow manner ... They may be lazier at work ... so I was a bit worried at the beginning. [F11L, Team 4].

Language Barriers. IE students emphasized that there were language barriers to their own integration into their respective teams, reflecting their inability to communicate in Cantonese. Ironically, some IE students reported that they had chosen Hong Kong as the place for their exchange because they had assumed that English is widely spoken in Hong Kong. For example:

I had chosen to come to Hong Kong because I thought people here speak English like they do in Singapore. [M20E, France, Team 1].

Our home university told us that everyone speaks English here in Hong Kong. [F1E, USA, Team 3].

Some IE students found it unfortunate that they had targeted an English medium host university for their exchange program but had discovered that local students were reluctant to speak English and that many people from the wider community could not speak English. Their comments included the following:

Not many people speak English here, for example none of the security guards speaks English. I wish my home university could have taught us Cantonese before we came here. [F1E, USA, Team 3]. 
The language barrier was especially salient in the context of those SL projects, which required collaboration with locally based external stakeholders who did not speak English. For example:

I don't speak Cantonese and when I met with the police, I found that one of the officers did not speak English very well. When my teammates were discussing statistics [in Cantonese], I just sat there. And the elderly [service recipients] didn't speak English very well. That was hard. [F1E, Team 3, USA].

The [POR] spoke to us in Cantonese, and after this orientation meeting, which overran, one IE student asked not to get involved the next time. This member did not show up at the next meeting. The other two IE students joined three out of the six meetings. [M19L, Team 1].

A local student mentioned that older members of the local community overwhelmingly preferred to communicate in Cantonese rather than in English:

Only two or three elderly people could understand simple English. Most did not understand English. Our communication language was mainly Cantonese. Therefore, the two exchange students did not understand what we were talking about, including the feedback from the elderly people. [F24L, Team 2].

Although English is the formal medium of instruction at the host university, several informants reported that their local team members initially failed to respond to the IE students' need for them to speak in English and preferred either to continue speaking in Cantonese or to curtail their own contributions. For example:

If several times I hadn't expressed myself well [in English], I preferred to keep silent. At several meetings, I was relatively quiet and would only talk when called upon. I would not initiate to express my opinions actively. [M19L, Team 1].

I dislike talking in English and have a fear of speaking English. We [locals] were worried about conversing [with the IE students]. [F24L, Team 2].

All meetings were in Cantonese and I did not understand the reason why they could not do it in English ... From the beginning, most important ideas and decisions were taken in Cantonese. [F9E, France, Team 4].

Some local students mentioned that it was difficult for them to understand the spoken English of the IE students from non-Anglo countries because of their distinctive accents. For example:

We discovered that we had very different accents. At first, we could not understand the spoken English between us. Therefore, communication became a serious issue. [M19L, Team 1]. 


\section{Overcoming the Barriers}

Local students adopted various methods for overcoming interpersonal barriers vis-à-vis the IE students. These included (a) appreciating the strengths of the IE students, (b) holding premeetings, (c) reaching out to IE students and inviting them to engage, (d) conducting team meetings entirely in English, (e) finding non-verbal roles for the IE students during episodes of direct service, and (f) providing simultaneous interpretation during direct service. IE students contributed to the development of cohesiveness by (a) exercising forbearance and good humor, (b) joining in using electronic media, and (c) compromising when scheduling meetings. These various approaches are illustrated below.

Appreciating the Strengths of IE Students. We list two comments, one indicating appreciation for IE students' perceived creativity, the other appreciating their perceived proactivity and citizenship behavior:

If the instructor assigns us a topic to work on, we Chinese will focus narrowly on that topic, while IE students will go beyond the frame. If asked for any new methods, Chinese will stick with obvious solutions, whereas IE students will think of new methods. [M19L, Team $1]$.

They [IE students] took initiative to express their views about what actions they would take, and they would not wait for us to assign tasks to them. They were nice when we communicated. They were responsible and punctual. They came on time for meetings; we didn't need to urge and remind them. They would respect the deadlines. We were very lucky. [F25L, Team 2].

Holding Pre-meetings. Local students in one team initially sought to overcome the language barrier by holding separate meetings with local students prior to meetings of the whole team:

We local students had our own sub-group meeting first before we talked to the [IE] students. There were more things to do when we worked with them. Sometimes, we needed to explain several times before they could understand. [L25, Team 2].

Reaching Out to IE Students and Inviting Them to Engage. A local student explained that she and the other local students in her team realized that unless they deliberately drew the IE students into team discussions, the latter would continue to engage in withdrawal behavior:

We needed to initiate to speak to them [the IE students] to encourage them to work with us. We understood that in a strange and new environment, the [IE] students will tend to gather together. If we had not taken the initiative, it would have been more difficult to cooperate together in our project work. [F2L, Team 3]. 
Conducting Team Meetings Entirely in English. In three teams (Teams 1-3), those local students, who were initially reluctant to communicate in English during team meetings, eventually joined their peers in doing so. Illustrative comments were:

I suggested to team members that it would be better for everyone to use English to communicate as we were an international team ... In the beginning, the female members did not want to speak in English. I encouraged them to speak more. [Eventually]... they improved and became more willing to speak more in English. [M18L, Team 1].

When we lapsed into using Chinese again sometimes, [M18L] would remind us not to do so. Another two local female members and I would sometimes forget to write in English. With prompt reminders by [M18L], we would rewrite again promptly in English. [M19L, Team 1].

At first, one of the team members spoke some Chinese. We reminded this person to speak more English and eventually we were all speaking English. [F2L, Team 3].

Finding Non-Verbal Roles for The IE Students during Direct Service. A local student explained:

[During the service delivery], the IE students did not need to speak but they could mime the actions to be taken and they were willing to take up this role. [M18L, Team 1].

Providing Simultaneous Interpretation During Direct Service. In at least one team, local students provided simultaneous interpretation during meetings with service recipients:

We do not speak Cantonese and we had to make our presentation [to elderly people] in English. The female local students had to serve as interpreters. We made PowerPoint presentation slides in English for the elderly and the female students translated them into Chinese. [M23E, Germany, Team 2].

The service was not hard for us to deliver, and the elderly people were really nice. We had conversations with them. [M22E, Germany, Team 2].

We [local students] found that we could perform a translation role effectively between the IE students and the elderly people. We were able to translate clearly as those, who did not understand English could follow us. The elderly people were excited to meet the [IE] students. They said, 'Oh! Foreign people! Very handsome!' ... Those, who could speak English went to speak to them [IE students] in English during the break for a long time and we did not need to translate for them. We even took a video of their conversations. They talked very happily. During the last two workshops, the handouts were bi-lingual. [F24L, Team 2].

Forbearance and Good Humor. Some IE students were described as having contributed to the building of cohesiveness by being sensitive to local students' difficulties with spoken English 
and being patient and good-humored in trying to ensure that everyone could understand them and feel at ease with them. For example:

With local students, I speak more carefully. Otherwise you can say something that can offend someone because they misunderstand something you say and something like that. [M20E, France, Team 1].

In Sweden, I would be more aggressive as you can communicate easier. But here, I try to be more collaborative and be more open. It is a different culture, and everything is different. When you ask locals "What do you think?" they don't like to respond so much. Maybe they don't know or maybe they don't want to share their ideas. You really have to persuade them really much to get some answers. [M21E, Sweden, Team 1].

We would make some jokes, so the whole atmosphere was good. Casual and fearless and so on. We showed the local students that we are normal people and don't harm anyone ...We tried to show our best side. [M23E, Germany, Team 2].

The two exchange students were funny and nice. We gradually came to talk to each other on topics not associated with the project. We would make friendly jokes and also played together. The atmosphere was harmonious. [F24L, Team 2].

Eventually we found that they [IE students] were nice. We [local students] started to talk more with them and established better relationships. With better relationships, we talked even more. [F25L, Team 2].

They [IE students] also worked hard to cooperate with us ...We also chatted sometimes about the places that they had visited. They shared photos and we had leisure time together and so the feeling towards them changed. [F3L, Team 3].

I tried to slow down the conversation and saw whether they [local students] understood or not. If they didn't, I tried to explain with simpler words, or asked others to help. [F4E, Portugal, Team 3].

Joining in Using Electronic Media. One IE student mentioned the following:

We could communicate in English through Facebook and WhatsApp. Communication was quite good. [M20E, France, Team, 1].

Compromising on the Scheduling of Meetings. A typical comment was:

The IE students came to accept having meetings after 8:00 p.m. during the week. This was already their maximum adjustment ... But they still could not accept having project meetings during weekends. We gave way to them about that. [M19L, Team 1].

Developmental Outcomes Associated with Cross-Cultural Cohesiveness 
In the three teams where the students had recognized the importance of overcoming barriers to cohesiveness and had apparently overcome them or had made progress in overcoming them, the main developmental outcomes associated with cross-cultural team experience that they reported were improved English, interpersonal adaptability, and appreciation of diversity.

Improved English. Local and IE students (from non-Anglo countries) alike reported that their English had improved. For example:

Now, after more practice in using English to speak to them [IE students], my confidence has increased. In the past, when making presentations, I needed to read out the script. However, during my presentation yesterday, I did not use a script. This is the biggest improvement for me during this semester. [M19L, Team 1].

I rarely speak English with anyone in my home country, and so here I have been able to improve my English. I speak English more fluently now than before. [M21E, Sweden, Team 1].

Yes. I have improved my language. Since I often talked with the exchange students, my English has improved a lot. [F24L, Team 2].

I improved my English a lot here also. [F4E, Portugal, Team 3].

Interpersonal Adaptability and Appreciation of Diversity. In Teams 1, 2, and 3, once the IE students had developed a more complete understanding of the service needs and service context associated with their respective SL projects, they could work more effectively with the local students to address shared project objectives. Mutual project engagement enabled local and IE students alike to appreciate the insights arising from cross-cultural sharing, decision-making, and problem solving:

I benefited from the experience here working with people from a different culture with different working styles and different attributions and everything, and so I learned to adapt even with people not of my style. [M21E, Team 1].

After this experience, [I realize that] it is helpful working with [IE] students. We can widen our knowledge horizon through our diversity and different ideas. [F24L, Team 2].

I think they [local students] are also much more open-minded. They were so shy in the beginning ... They were not good English speakers, but we also were not that self-confident at the beginning. I think nowadays they have no problems to talk to us. No problem. This team was very good. [M22E, Germany, Team 2].

For us, it is more important to share our cultural experiences. Also, we came here to see the Hong Kong culture, the Chinese culture, so it is really nice to talk to them [local students]. [M23E, Germany, Team 2]. 


\section{Discussion and Contributions}

We found that although language proficiency gaps constituted a major barrier to the development of cross-cultural cohesiveness, these gaps could be offset by adopting appropriate communication strategies within the teams. These findings are comparable with those of Imamura et al. (2016), who found that the inclusion of communication variables other than linguistic proficiency may provide a more conclusive picture of how intergroup contact theory works in an intercultural context. They further proposed that future studies should examine intergroup contact theory from the perspective of Americans staying in East Asian locations as well as East Asians' perceptions of Americans staying there with the aim of extending the scope of the theory in an intercultural context. Our research has focused on the intercultural experiences of students in Hong Kong from the perspective of both local students and IE students with an American among the latter.

\section{Theoretical Contributions}

We shall recap Allport's (1954) four conditions for prejudice reduction, which by implication would be conducive to the reduction of cross-cultural barriers and to the development of team cohesiveness among the local and IE students. These conditions are (1) authority support, (2) equal status, (3) intergroup cooperation, and (4) common goals. As explained next, while the university and/or the instructors sought to provide a supportive framework for these four conditions, the realization thereof depended on communicative initiatives and acts of reciprocation among the team members.

Regarding the first condition, by opening registration on SL courses to IE students, the university provided legitimation for the community involvement of IE students, but when the teams were working at the community sites, the PORs, by speaking Cantonese only, left it to the teams themselves to work out how to support the community involvement of the IE students.

Regarding condition two, by applying the same assignment and grading structure to local and IE students alike, the university may have assumed that both groups of students would be afforded equal status on the SL courses. In practice, however, the ability of the IE students to access project information, and to contribute to project decision making depended upon the willingness of the local students to adopt English as the medium for team discussion. Regarding conditions three and four, by arranging for the teams to comprise a mixture of local and IE students, instructors created a framework for cooperation between the two subgroups in working toward common goals including satisfaction of community expectations regarding the SL projects. Once again, the ability of IE students to cooperate with the local students depended on the latter's willingness to communicate in English, while in addition, sustained cooperation depended on the IE students' willingness to reciprocate by, for example, offering creative ideas, exercising forbearance and good humor, and compromising about the scheduling of meetings. 
Our study thus indicates that the reduction of cross-cultural barriers between local and IE students, and the developmental outcomes arising from team cohesiveness, depend on the emergence of mutual goodwill among the participants, in this case, students, through acts of initiative and reciprocation.

\section{Practical Implications}

Cultural preferences. Prior commentators have proposed some university level approaches for preparing IE students for engagement in cross-cultural project teams. Almeida et al. (2016) suggested that IE students could be introduced to dimensions of cultural preferences, such as individualism vs collectivism, as a means for understanding potential sources of cross-cultural conflicts. Sato and Hodge (2015) suggested that IE students should be primed to reframe crosscultural stressors as opportunities for personal and professional growth. We believe that these measures would be constructively reinforced if they were adopted by both home and host universities as part of their programs for both outgoing and incoming IE students.

Contact relationships. We have some suggestions, based on our research, about building a foundation for high quality contact relationships within mixed SL teams. The host university could include information about the team-related obligations entailed by enrolling in an SL course in its briefing materials and induction programs. At the course level, we suggest that a team building session be provided by a supporting unit (e.g. office of service-learning) early in the semester to alert students to the importance of adopting and practicing skills of reaching out to, listening to, and resolving conflicts with peers. This arrangement may be especially important if teamwork is not the topic of the course. Instructors are also advised continually to encourage students to recognize the potential benefits of cultural diversity as a resource for teams.

Language barriers. We recommend that instructors of SL courses remind students that if they are in cross-culturally mixed teams, it is vital to hold team meetings in a language medium that is well-understood by all team members, which typically would be English. Instructors may also encourage local students in mixed teams to provide interpretation services for IE students when their team is interacting with service recipients who do not speak that language. Host universities that offer SL courses could incorporate these ideas into their guidelines for instructors. Alternatively, or in addition, host universities that offer programs in translation could find ways to arrange for students, who are majoring in translation to provide the necessary translation services as part of their own project work requirements.

Personality factors. We consider it important that prospective IE students are screened by the home university for their readiness to participate in an IE program. In addition, in view of the apparent marginalization of one of the IE students in our study, we suggest that at the course level, when forming SL teams with local and IE students, where possible it is advisable to avoid having only one IE student in a team, unless that student already appears to have strong 
intercultural skills. Instructors of SL courses are also advised to monitor the team participation of their IE students and to provide advocational support if it appears that they are being marginalized during team discussions.

\section{Limitations and Further Research}

This research was limited to two courses at a single host university site. There may be different findings with SL courses on other subjects at the same site and at other host universities in Hong Kong or elsewhere. Studies of projects undertaken by inter-cultural SL teams on various courses at host universities in other jurisdictions would facilitate the generalizability of the findings. As the use of social media in education becomes more extensive, it would also be interesting to conduct further investigations into how the use of social media for communication within intercultural SL teams, and even for communication between such teams and their community stakeholders and end-beneficiaries, can facilitate or hinder the development of team cohesiveness. Further studies of the development of cohesiveness in intercultural SL teams with differing proportions of local and IE students could also be conducted. Longitudinal studies including the post-sojourner stage, covering the period when IE students have returned to their home countries, would reveal their perceptions of the long-term impact on their development of participating in intercultural SL teams with varying degrees of cohesiveness. Instruments such as S-LOMS (Lau \& Snell, 2021; Snell \& Lau, 2020) could be used to compare the self-perceived developmental impact on students of conducting SL in teams comprised entirely of local students versus in intercultural teams.

\section{Conclusion}

This study of four cross-cultural teams engaged in SL indicated that although informants identified various barriers to cross-cultural collaboration, in two teams these barriers were overcome, while some progress was made in developing cohesiveness between local and IE students in a third team. Breaking down language-related barriers required extra effort from the local students and patience and good-humor on the part of the IE students. In addition, compromises were necessary regarding the arrangement of meeting times and the setting of deadlines for project contributions. Resolving scheduling conflicts required team members to express their own needs and concerns openly as well as to appreciate the needs and concerns of others.

In the three teams that had made progress in developing cross-cultural cohesiveness, it appeared that cross-cultural diversity became a source of inspiration and fruitful ideas. Among members of these teams, IE and local students alike perceived their skills of English communication had been sharpened. Some IE students felt that they had acquired deeper understanding of the local culture while some local students stated that they had overcome anxieties associated with interacting with foreigners.

(C) The Author 2021. Published by the Coalition of Urban and Metropolitan Universities. www.cumuonline.org Metropolitan Universities | DOI 10.18060/24272 | February 15, 2021 


\section{References}

Allport, G. W. (1954). The nature of prejudice. Perseus Books.

Almeida, J., Fantini, A. E., Simões, A. R., \& Costa, N. (2016). Enhancing the intercultural effectiveness of exchange programmes: formal and non-formal educational interventions. Intercultural Education, 27(6), 517-533. doi: 10.1080/14675986.2016.1262190

Batchelder, T., \& Root, S. (1994). Effects of an undergraduate program to integrate academic learning and service: Cognitive, prosocial cognitive, and identity outcomes. Journal of Adolescence, 17(4), 341-355. doi: 10.1006/jado.1994.1031

Barna, L. M. (1997) Stumbling blocks in intercultural communication. In L. A. Samovar \& R. E. Porter. Intercultural communication ( $8^{\text {th }}$ ed.). Wadsworth Publishing.

Bitner, M. J., Booms, B. H., \& Tetreault, M. S. (1990). The service encounter: Diagnosing favorable and unfavorable incidents. Journal of Marketing, 54(1), 71-84. doi: $10.2307 / 1252174$

Boje, D. M. (2001). Narrative methods for organization research and communication research. Sage.

Brail, S. (2016). Quantifying the value of service-learning: A comparison of grade achievement between service-learning and non-service-learning students. International Journal of Teaching and Learning in Higher Education, 28(2), 148-157

Braun, V., \& Clarke, V. (2006). Using thematic analysis in psychology. Qualitative Research in Psychology, 3(2), 77-101. doi:10.1191/1478088706qp063oa

Brooks, R., Byford, K., \& Sela, K. (2015). Inequalities in students' union leadership: The role of social networks. Journal of Youth Studies, 18(9), 1204-1218. doi: 10.1080/13676261.2015.1039971

Campion, M. A., Medsker, G. J., \& Higgs, A. C. (1993). Relations between work group characteristics and effectiveness: Implications for designing effective work groups. Personnel Psychology, 46(4), 823-850.

Carron, A. V., \& Brawley, L. R. (2000). Cohesion: Conceptual and measurement issues. Small Group Research, 31(1), 89-106. doi: 10.1111/j.1744-6570.1993.tb01571.x

Chak, M. K. A., \& Makino, S. (2010). Are we making the right choice to go for international exchange programs? Journal of International Business Education, 5, 145-160.

Chelliah, S., Khan, M., Krishnan, T., Kamarulzaman, M., \& Goh, N. (2018). Factors influencing satisfaction and revisit intention among international exchange students in Malaysia.

(C) The Author 2021. Published by the Coalition of Urban and Metropolitan Universities. www.cumuonline.org

Metropolitan Universities | DOI 10.18060/24272 | February 15, 2021 
Journal of International Education in Business, 12(1), 111-130. doi: 10.1108/JIEB-072018-0026

Conner, J., \& Erickson, J. (2017). When does service-learning work? Contact theory and servicelearning courses in higher education. Michigan Journal of Community Service Learning, 23(2), 53-65. doi: 10.3998/mjcsloa.3239521.0023.204

Conway, J. M., Amel, E. L., \& Gerwien, D. P. (2009). Teaching and learning in the social context: A meta-analysis of service learning's effects on academic, personal, social, and citizenship outcomes. Teaching of Psychology, 36(4), 233-245. doi: 10.1080/00986280903172969

Creswell, J. W. (1998) Qualitative inquiry and research design: Choosing among five traditions. London: Sage.

DiCecco, J., Silva, S., Coughlin, J., Swaby, T., Wu, J., Sun, Y., Kuwasawa, K., \& Hill, R. (2004). Experiential learning in neurophysiology for undergraduate biomedical engineering. Paper presented at the IEEE 30th Annual Northeast Bioengineering Conference, Springfield, NA. doi: 10.1109/NEBC.2004.1300075

Falk, A. (2012). Enhancing the team experience in service learning courses. Journal for Civic Commitment, 18(1), 1-18.

Fincher, R, \& Shaw, K. (2009). The unintended segregation of transnational students in central Melbourne. Environment and Planning A, 41(8), 1884-1902. doi: 10.1068/a41126

Gallarza, M. G., Seric, M., \& Cuadrado, M. (2017). Trading off benefits and costs in higher education: A qualitative research with international incoming students. The International Journal of Management Education, 15(3), 456-469. doi: 10.1016/j.ijme.2017.08.001

Gilbert, B. L., Banks, J., Houser, J. H. W., Rhodes, S. J., \& Lee, N. D. (2014). Student development in experiential learning program. Journal of College Student Development, 55(7), 707-713. doi: 10.1353/csd.2014.0072

Greenbaum, T. (1998) The handbook for focus group research ( $2^{\text {nd }}$ ed.). Sage.

Hodson, G., \& Dhont, K. (2015). The person-based nature of prejudice: Individual difference predictors of intergroup negativity, European Review of Social Psychology, 26(1), 1-42. doi: $10.1080 / 10463283.2015 .1070018$

Hofstede, G. J. (2001). Culture's consequences: Comparing values, behaviors, institutions, and organizations across nations ( 2 nd ed.). Sage.

Hofstede, G. J. (2005). Cultures and organizations: Software of the mind (2nd ed.). McGrawHill. 
Imammura, M., Ruble, R., \& Zhang, Y. (2016). English proficiency, identity, anxiety, and intergroup attitudes: US Americans' perceptions of Chinese. Journal of Intercultural Communication Research, 45(6), 526-539. doi: 10.1080/17475759.2016.1240704

Jang, D., \& Kim, D. Y. (2010). The influence of host cultures on the role of personality in the acculturation of exchange students. International Journal of Intercultural Relations, 34(4): 363-367. doi: 10.1016/j.ijintrel.2009.12.002

Jehn K. A., Neale, M., \& Northcraft, G. (1999). Why differences make a difference: a field study of diversity, conflict, and performance in workgroups. Administrative Science Quarterly, 44(4), 741-763. doi: 10.2307/2667054

Keles, Y. (2013). What intercultural communication barriers do exchange students of Erasmus Program have during their stay in Turkey, Mugla? Procedia - Social and Behavioral Sciences, 70, 1513-1524. doi: 10.1016/j.sbspro.2013.01.219

Kim, Y. Y. (2001). Becoming intercultural: An integrative theory of communication and crosscultural adaptation. Sage.

Kvale, S. (1996). InterViews: An introduction to qualitative research interviewing. Sage.

Lagerstrom, K., \& Andersson, M. (2003). Creating and sharing knowledge within a transnational team: The development of a global business system. Journal of World Business, 38(2), 84-95. doi: 10.1016/S1090-9516(03)00003-8

Lau K. H. \& Snell R. S. (2021). Confirmatory factor analysis for a service-learning outcomes measurement scale (S-LOMS). Metropolitan Universities, 32(1), 3-34. doi: $10.18060 / 23920$.

Ladegaard, H. (2015). Personal experience and cultural awareness as resources in teaching intercultural communication: A Hong Kong case study. In G. Slethaug \& J. Vinther (Eds.). International teaching and learning at universities: Achieving equilibrium with local culture and pedagogy (pp. 112-134). Palgrave Macmillan.

Lauring, J., \& Selmer, J. (2010). Multicultural organizations: Common language and group cohesiveness. International Journal of Cross Cultural Management, 10(3), 267-284. doi: $10.1177 / 1470595810384587$

LeFebvre, R. \& Franke, V. (2013). Culture matters: Individualism vs. collectivism in conflict decision-making. Societies, 3(1), 128-146. doi:10.3390/soc3010128

McKinlay, N. J., Pattison, H. M., \& Gross, H. (1996). An exploratory investigation of the effects of a cultural orientation programme on the psychological well-being of international university students. Higher Education, 31(3), 379-395. doi: 10.1007/BF00128438 
Müceldili, B., \& Erdil, O. (2015). Cultivating group cohesiveness: The role of collective energy. Procedia - Social and Behavioral Sciences, 207, 512-518. doi:

10.1016/j.sbspro.2015.10.121

Nibler, R., \& Harris, K. (2003). The effects of culture and cohesiveness on intragroup conflict and effectiveness. The Journal of Social Psychology, 143(5), 613-631. doi: $10.1080 / 00224540309598467$

Niehaus, E. \& Crain, L. K. (2013). Act local or global? Comparing student experiences in domestic and international service-learning programs. Michigan Journal of Community Service Learning, 20(1), 31-40.

Ötkan, C. Ç., Demir, G. T., \& Halıcı, A. (2017). Examination of group cohesiveness levels and goal orientations of basketball players. SHS Web of Conferences, 37, 1041. doi: $10.1051 /$ shsconf $/ 2017370$

Pettigrew, T. (2008). Future directions for intergroup contact theory and research. International Journal of Intercultural Relations, 32(3), 187-199. doi: 10.1016/j.ijintrel.2007.12.002

Pitts, M. (2009). Identity and the role of expectations, stress, and talk in short-term student sojourner adjustment: An application of the integrative theory of communication and cross-cultural adaptation. International Journal of Intercultural Relations, 33(6), 450462. doi: 10.1016/j.ijintrel.2009.07.002

Quinn, R. W., \& Dutton, J. E. (2005). Coordination as energy-in-conversation. The Academy of Management Review, 30(1), 36-57. doi: 10.5465/amr.2005.15281422

Riordan C.M. \& Weatherly E. W. (1999), Defining and measuring employees' identification with their work groups. Educational and Psychological Measurement, 59 (2), 310-324. doi: $10.1177 / 00131649921969866$

Ryan, J. (2016). 'Asian' learners or 'internationalised' learners? Taking advantage of international cultural academic flows. East Asia, 33(1), 9-24. doi: 10.1007/s12140-0159246-2

San Antonio, L. M., \& Ofori-Dwumfuo, C. (2015). Understanding communication dynamics among international and domestic students: A case study of a global living-learning community. Journal of College and University Student Housing, 42(1), 128-143.

Sato, T., \& Hodge, S. R. (2013). Japanese students' academic and social experiences at a predominantly white university in the United States. Journal of Multicultural Learning and Teaching, 8(1), 93-114. doi: 10.1515/mlt-2012-0040

Sato, T., \& Hodge, S. (2015). Academic and social experiences of exchange students from Japan attending an American University. College Student Journal, 49(1), 78-92. 
Snell, R. S., Chan, M. Y. L., Ma, C. H. K., \& Chan, C. K. M. (2015). A road map for empowering undergraduates to practice service leadership through service-learning in teams. Journal of Management Education, 39(3), 372-399. doi:

$10.1177 / 1052562914545631$

Snell, R. S., \& Lau, K. H. (2020). The development of a service-learning outcomes measurement scale (S-LOMS). Metropolitan Universities, 31(1), 44-77. doi: 10.18060/23258

Terry, G., Hayfield, N., Clarke, V., \& Braun, V. (2017). Thematic analysis. In W. Stainton Rogers \& C. Willig (Eds.). The SAGE handbook of qualitative research in Psychology (pp. 17-37). (2 ${ }^{\text {nd }}$ ed.). SAGE Publications.

Tian, X. (2019). Space and personal contacts: Cross-group interaction between mainland and local university students in Hong Kong. Journal of Social and Personal Relationships, 36(1), 63-82. doi: 10.1177/0265407517718967

Triandis, H. C., Botempo, R., Villareal, M.J., Asai, M., \& Lucca, N. (1988). Individualism and collectivism: Cross-cultural perspectives on self-ingroup relationships. Journal of Personality and Social Psychology, 54(2), 323-338. doi: 10.1037/0022-3514.54.2.323

Waters, J., \& Brooks, R. (2011). 'Vive la différence'? The "international” experiences of UK students overseas. Population, Space and Place, 17, 567-578. doi:10.1002/psp.613

Wen, W., Hu, D., \& Hao, J. (2018). International students' experiences in China: Does the planned reverse mobility work? International Journal of Educational Development, 61, 204-212. doi: 10.1016/j.ijedudev.2017.03.004

Wendt H., Euwema M.C., \& Emmerik I. J. H. (2009). Leadership and team cohesiveness across cultures. The Leadership Quarterly, 20(3), 358-370. doi: 10.1016/j.leaqua.2009.03.005

Williams, E., Duray, R., \& Reddy, V. (2006). Teamwork orientation, group cohesiveness, and student learning: A study of the use of teams in online distance education. Journal of Management Education, 30(4), 592-616. doi: 10.1177/1052562905276740

Wilson, J. (2011). Service-learning and the development of empathy in US college students. Education Training, 53(2/3), 207-217. doi: 10.1108/00400911111115735

Yakuina, E. S., Weigold, I. K., Weigold, A., Harcegovac, S., \& Elsayed, N. (2013). International students' personal and multicultural strengths: Reducing acculturative stress and promoting adjustment. Journal of Counseling \& Development, 91(2), 216-223. doi: 10.1002/j.1556-6676.2013.00088.x

Yorio, P. L. \& Ye, F. (2012). A meta-analysis on the effects of service-learning on the social, personal, and cognitive outcomes of learning. Academy of Management Learning \& Education, 11(1), 9-27. doi: 10.5465/amle.2010.0072 